Claudio Sandroni

Alain Cariou

Fabio Cavallaro

Tobias Cronberg

Hans Friberg

Cornelia Hoedemaekers

Janneke Horn

Jerry P. Nolan

Andrea O. Rossetti

Jasmeet Soar

\section{Prognostication in comatose survivors of cardiac arrest: An advisory statement from the European Resuscitation Council and the European Society of Intensive Care Medicine}

Received: 20 August 2014

Accepted: 22 August 2014

Published online: 15 November 2014

(C) The Author(s) 2014. This article is published with open access at

Springerlink.com

This statement has been endorsed by the European Resuscitation Council (ERC) and the European Society of Intensive Care Medicine (ESICM) and is being jointly published in Resuscitation and Intensive Care Medicine. Originally published in Resuscitation [doi:10.1016/j.resuscitation. 2014.08.011]; published with kind permission of Elsevier Ireland Ltd. All Commercial Rights Reserved.

Electronic supplementary material

The online version of this article (doi:10.1007/s00134-014-3470-x) contains supplementary material, which is available to authorized users.

\section{Sandroni $(\bowtie) \cdot$ F. Cavallaro}

Department of Anaesthesiology and Intensive Care, Catholic University School of Medicine, Largo Gemelli 8, 00168 Rome, Italy

e-mail: sandroni@rm.unicatt.it

\section{A. Cariou}

Medical ICU, Cochin Hospital (APHP), Paris Descartes University, Paris, France

\section{T. Cronberg}

Department of Clinical Sciences, Division of Neurology, Lund University, Lund, Sweden

\section{H. Friberg}

Anaesthesiology and Intensive Care

Medicine, Skåne University Hospital, Lund University, Lund, Sweden
C. Hoedemaekers

Intensive Care, Radboud University, Nijmegen Medical Centre, Nijmegen, The Netherlands

\section{J. Horn}

Intensive Care, Academic Medical Center, Amsterdam, The Netherlands

\section{J. P. Nolan}

Department of Anaesthesia and Intensive Care Medicine, Royal United Hospital, Bath, UK

\section{A. O. Rossetti}

Department of Clinical Neurosciences, CHUV and University of Lausanne, Lausanne, Switzerland

J. Soar

Department of Anaesthesia and Intensive Care Medicine, Southmead Hospital, Bristol, UK

Abstract Objectives: To review and update the evidence on predictors of poor outcome (death, persistent vegetative state or severe neurological disability) in adult comatose survivors of cardiac arrest, either treated or not treated with controlled temperature, to identify knowledge gaps and to suggest a reliable prognostication strategy.

Methods: GRADE-based systematic review followed by expert consensus achieved using Web-based Delphi methodology, conference calls and face-to-face meetings. Predictors based on clinical examination, electrophysiology, biomarkers and imaging were included. Results and conclusions: Evidence from a total of 73 studies was reviewed. The quality of evidence was low or very low for almost all studies. In patients who are comatose with absent or extensor motor response at $\geq 72 \mathrm{~h}$ from arrest, either treated or not treated with controlled temperature, bilateral absence of either pupillary and corneal reflexes or N20 wave of shortlatency somatosensory evoked potentials were identified as the most robust predictors. Early status myoclonus, elevated values of neuron-specific enolase at $48-72 \mathrm{~h}$ from arrest, unreactive malignant EEG patterns after rewarming, and presence of diffuse signs of postanoxic injury on either computed tomography or magnetic resonance imaging were identified as useful but less robust predictors. Prolonged observation and repeated assessments should be considered when results of initial assessment are inconclusive. Although no specific combination of predictors is sufficiently supported by available evidence, a multimodal prognostication approach is recommended in all patients.

Keywords Heart arrest - Coma . Prognosis - Clinical examination . Somatosensory evoked potentials . Neuron specific enolase - CT scan . Magnetic resonance 


\section{Introduction}

Severe neurological impairment caused by hypoxic-ischaemic brain injury is common after resuscitation from cardiac arrest [1]. Early identification of patients with no chance of a good neurological recovery will help to avoid inappropriate treatment and provide information for relatives.

In 2006 [2], a landmark review from the Quality Standards Subcommittee of the American Academy of Neurology (AAN) recommended a sequential algorithm to predict poor neurological outcome in comatose survivors within the first $72 \mathrm{~h}$ after cardiopulmonary resuscitation (CPR). According to that algorithm, the presence of myoclonus status epilepticus on day 1, the bilateral absence of the N20 wave of somatosensory evoked potentials (SSEPs) or a blood concentration of neuron specific enolase (NSE) above $33 \mu \mathrm{g} \mathrm{L}^{-1}$ at days $1-3$, and absent pupillary and corneal reflexes or a motor response no better than extension (M1-2) at day 3 accurately predicted poor outcome. However, the AAN recommendations need updating:

1. The AAN 2006 review was based on studies conducted before the advent of therapeutic hypothermia $(\mathrm{TH})$ for post-resuscitation care. Both $\mathrm{TH}$ itself and sedatives or neuromuscular blocking drugs used to maintain it may potentially interfere with prognostication indices, especially clinical examination [3]. The predictive value of those indices therefore needs to be reevaluated in TH-treated patients.

2. Studies conducted both before [4] and after [5, 6] the AAN 2006 review showed that the previously recommended thresholds for outcome prediction using biomarkers were inconsistent [7].

3. Evidence for some prognostic tools such as EEG [8] and imaging studies was limited at the time of the 2006 AAN review, and needs re-evaluation.

4. The AAN 2006 review and previous reviews did not adequately address some important limitations of prognostication studies, such as the risk of 'selffulfilling prophecy', which is a bias occurring when the treating physicians are not blinded to the results of the outcome predictor and use it to make a decision to withdraw life-sustaining treatment (WLST) [9].

Given the limitations of the current literature and the need for up-to-date clinical guidance, members of the European Resuscitation Council (ERC) and the Trauma and Emergency Medicine (TEM) Section of the European Society of Intensive Care Medicine (ESICM) planned an Advisory Statement on Neurological Prognostication in comatose survivors of cardiac arrest. The aims of this statement are to:

1. Update and summarize the available evidence on this topic, including that on $\mathrm{TH}$-treated patients;
2. Provide practical recommendations on the most reliable prognostication strategies, based on a more robust analysis of the evidence, in anticipation of the next ERC Guidelines on Resuscitation to be published in October 2015;

3. Identify knowledge gaps and suggest directions for future research.

\section{Methods}

\subsection{Panel selection}

The panel for this Advisory Statement included medical specialists experienced in the management of comatose resuscitated patients. All the panel members are authors of original studies on prognostication in post-resuscitation care or have previous experience in guideline development or systematic evidence review. Panel members completed a conflict of interest declaration, as recommended $[10,11]$.

\subsection{Group process}

Following an initial conference call and a face-to-face meeting, the panel members agreed on criteria for study inclusion, grading methods, and the process timeline. Subsequent consensus on the evidence and the recommendations was achieved using a Web-based Delphi method. The document was written using a Web-based collaborative process and collectively reviewed for content and wording. A final face-to-face meeting was held to finalize the statements.

\subsection{Inclusion criteria and definitions}

Given the paucity of evidence on neurological prognostication in children with coma after cardiac arrest, the evidence evaluation was restricted to adults. Inclusion criteria are described in detail elsewhere [12]. Briefly, all studies on adult ( $\geq 16$ years) patients who were comatose following resuscitation from cardiac arrest and were treated with TH were considered for inclusion. Patients defined as unconscious, unresponsive, or having a Glasgow Coma Scale score (GCS) [13] $\leq 8$, were considered as comatose. Studies including non-comatose patients or patients in hypoxic coma from causes other than cardiac arrest (e.g., respiratory arrest, carbon monoxide intoxication, drowning, and hanging) were excluded, except when a subpopulation of cardiac arrest patients could be evaluated separately.

Studies were considered for inclusion regardless of both the cause of arrest and treatment with TH. Pooling of 
data was stratified according to timing of prognostication and $\mathrm{TH}$ treatment. Poor neurological outcome was defined as a Cerebral Performance Category (CPC) [14] of 3-5 (severe neurological disability, persistent vegetative state or death) as opposed to CPC 1-2 (absent, mild or moderate neurological disability; see ESM Appendix 1 for a detailed CPC description). In some studies, a CPC 4-5 was defined as a poor outcome. When original data were not available to correct outcome as CPC 3-5, a CPC 4-5 was accepted as a surrogate poor outcome, assigning the study an indirectness score. When the outcome was expressed using a modified Rankin Score (mRS) [15], an equivalent CPC was calculated based on the equivalence $\mathrm{mRS} \geq 4=\mathrm{CPC} \geq 3[16]$.

\subsection{Data source}

Results from three recent systematic reviews [7, 12, 17] on post-arrest prognostication were used as a data source. One of these [7] included 50 studies on 2,828 patients not treated with $\mathrm{TH}$, the two other reviews $[12,17]$ included a total of 39 studies in 2,564 TH-treated patients. In order to identify further studies published during the grading and consensus process, the automatic alert system of PubMed was maintained active and the tables of contents of relevant journals were screened. This led to the inclusion of five additional studies [18-22].

\subsection{Grading}

Grading was made according to the Grading of Recommendations Assessment, Development and Evaluation (GRADE) criteria [23-28]. The grading process for included studies is described in detail in the ESM Appendix 2.

\subsubsection{Quality of evidence}

According to GRADE, the quality of evidence (QOE) was graded as high, moderate, low or very low according to the presence of limitations, indirectness, inconsistency, and imprecision. Publication bias was not considered, given the difficulty of measuring it in prognostic studies [29].

Given the importance of the risk of self-fulfilling prophecy, limitations were graded as serious when the treating team was not blinded to the results of the predictor of poor outcome that was being studied, and very serious when the investigated predictor was used to decide to WLST.

Imprecision was graded as serious when the upper limit of the $95 \%$ confidence intervals (CIs) of the estimate of the false positive rate (FPR) was greater than $5 \%$, and very serious when this value was more than $10 \%$. Confidence intervals were calculated using the $\mathrm{F}$ distribution method, according to Blyth [30].
This advisory statement covers the four main categories of prognostic tests: clinical examination, electrophysiology, biomarkers and imaging. The relevant Evidence Profile tables are included in the ESM Appendices 3a-d.

\subsection{Recommendations}

Recommendations in this document are stated as either strong ('we recommend') or weak ('we suggest') [24, 25]. The strength of the recommendations was based on the following factors [25]: (1) the balance between true and false predictions given by that test, i.e. the test performance as estimated by its sensitivity and specificity; (2) the confidence in the magnitude of the estimates (i.e., the quality of evidence); and (3) the resource use, i.e. the cost of the strategy under evaluation.

\section{Clinical examination}

\subsection{Evidence (ESM Table 1)}

\subsubsection{Ocular reflexes}

Bilateral absence of pupillary light reflex immediately after recovery of spontaneous circulation (ROSC) [31-33] has a very limited value in predicting poor outcome [FPR is 8 (1-25) \%]. Conversely, at $72 \mathrm{~h}$ from ROSC [3, 18, 33-40], a bilaterally absent pupillary light reflex predicts poor outcome with $0 \%$ FPR, both in TH-treated and in non-THtreated patients (95\% CIs $0-2$ and $0-8$, respectively); however, its sensitivity is low (24 and $18 \%$ respectively).

A bilaterally absent corneal reflex is slightly less specific than the pupillary reflex for prediction of poor outcome. One reason for this could be the sensitivity of the corneal reflex to interference from residual effects of sedatives [3] or neuromuscular blocking drugs. At $72 \mathrm{~h}$ from ROSC, the FPR was 5 (0-25) \% in one study [35] in non-TH-treated patients and $4(1-7) \%$ in 7 studies [3, 18, 36-40] in TH-treated patients; sensitivities were 29 and $34 \%$ respectively.

\subsubsection{Motor response to pain}

In non-TH-treated patients [35, 41], an absent or extensor motor response to pain, corresponding to a motor score 1 or 2 of the Glasgow Coma Scale $(M \leq 2)$ at $72 \mathrm{~h}$ from ROSC, has a high [74 (68-79) \%] sensitivity for prediction of poor outcome, but the FPR is also high [27 (12-48) \%]. Similar results were observed in TH-treated patients [3, 18, 36-40, 42-44]. Like the corneal reflex, the motor response can be suppressed by the effects of sedatives or neuromuscular blocking drugs [3]. 
Only a few prognostication studies $[3,18,21,38,42$, 44] reported suspension of sedation before clinical examination and no study ruled out residual effects of neuromuscular blocking drugs using objective measurements such as median nerve stimulation train-of-four. No study evaluated the interobserver agreement in clinical examination. In coma due to multiple causes, this agreement is only moderate (kappa from 0.42 to 0.79 ) [45].

While predictors of poor outcome based on clinical examination are inexpensive and easy to use, they cannot be concealed from the treating team and therefore their results may potentially influence clinical management and cause a self-fulfilling prophecy.

\subsection{Recommendations}

We recommend:

- Using the bilateral absence of both pupillary and corneal reflexes at $72 \mathrm{~h}$ or more from ROSC to predict poor outcome in comatose survivors from cardiac arrest, either TH-treated or non-TH-treated.

- Prolonging observation of clinical signs beyond $72 \mathrm{~h}$ when interference from residual sedation or paralysis is suspected, so that the possibility of obtaining false positive results is minimised.

We do not suggest using an absent or extensor motor response to pain $(M \leq 2)$ alone to predict poor outcome in those patients, given its high false positive rate. However, due to its high sensitivity, this sign may be used to identify the population with poor neurological status needing prognostication or to predict poor outcome in combination with other more robust predictors.

\subsection{Knowledge gaps}

- Prospective studies are needed to investigate the pharmacokinetics of sedative drugs and neuromuscular blocking drugs in post-cardiac arrest patients, especially those treated with controlled temperature.

- Clinical studies are needed to evaluate the reproducibility of clinical signs used to predict outcome in comatose post-arrest patients. In particular, clinical examination tends to underestimate the presence of pupillary reflex, which can be detected and quantified using pupillometry [46, 47].

\section{Myoclonus and status myoclonus}

\subsection{Evidence (ESM Table 1)}

Myoclonus is a clinical phenomenon consisting of sudden, brief, involuntary jerks caused by muscular contractions or inhibitions. A prolonged period of continuous and generalised myoclonic jerks is commonly described as status myoclonus. There is no definitive consensus on the duration or frequency of myoclonic jerks required to qualify as status myoclonus; however, in prognostication studies in comatose survivors of cardiac arrest, the minimum reported duration is $30 \mathrm{~min}$. The names and definitions used for status myoclonus vary among those studies (see ESM Appendix 4). Terms like status myoclonus, myoclonic status, generalised status myoclonicus, and myoclonus (or myoclonic) status epilepticus have been used interchangeably. Although the term myoclonic status epilepticus may suggest an epileptiform nature for this phenomenon, in post-anoxic comatose patients clinical myoclonus is only inconsistently associated with epileptiform activity on EEG [48, 49].

In comatose survivors of cardiac arrest treated with $\mathrm{TH}[21,42,44,48,50,51]$, the presence of myoclonic jerks (not status myoclonus) within $72 \mathrm{~h}$ from ROSC is not consistently associated with poor outcome [FPR 5 (3-8) \%; sensitivity $33 \%$ ]. In one study [36], the presence of myoclonic jerks within 7 days from ROSC was compatible with neurological recovery [FPR 11 (3-26) \%; sensitivity $54 \%$ ].

A status myoclonus starting within $48 \mathrm{~h}$ from ROSC was consistently associated with a poor outcome [FPR 0 $(0-4) \%$; sensitivity $15 \%$ ] in prognostication studies made in non-TH-treated patients [35, 52, 53], and is also highly predictive [FPR $0.5(0-3) \%$; sensitivity $16 \%$ ] in TH-treated patients [3, 48, 54]. However, several case reports of good neurological recovery despite an earlyonset, prolonged and generalised myoclonus have been published. In some of these cases, [55-60] myoclonus persisted after awakening and evolved into a chronic action myoclonus (Lance-Adams syndrome). In others [61, 62], it disappeared with recovery of consciousness. The exact time when recovery of consciousness occurred in these cases may have been masked by the myoclonus itself and by ongoing sedation.

\subsection{Recommendations}

We suggest:

- Using the term status myoclonus [52] to indicate a continuous and generalized myoclonus persisting for $\geq 30 \mathrm{~min}$ in comatose survivors of cardiac arrest.

- Using the presence of a status myoclonus within $48 \mathrm{~h}$ from ROSC in combination with other predictors to predict poor outcome in comatose survivors of cardiac arrest, either TH-treated or non-TH-treated.

- Evaluating patients with post-arrest status myoclonus off sedation whenever possible; in those patients, EEG recording can be useful to identify EEG signs of awareness and reactivity [61] and to reveal a coexistent epileptiform activity. 


\subsection{Knowledge gaps}

- A consensus-based, uniform nomenclature and definition for status myoclonus is needed.

- The distinctive pathophysiological and electrophysiological features of postanoxic status myoclonus, in comparison with more benign forms of myoclonus, like the Lance-Adams syndrome, need to be further investigated.

\section{Bilateral absence of SSEP N20 wave}

\subsection{Evidence (ESM Table 2)}

In non-TH-treated post-arrest comatose patients, bilateral absence of the N20 wave of short-latency somatosensory evoked potentials (SSEPs) predicts death or vegetative state (CPC 4-5) with $0(0-5) \%$ FPR as early as $24 \mathrm{~h}$ from ROSC $[35,63,64]$, and it remains predictive during the following $48 \mathrm{~h}$ with a consistent sensitivity (45-46\%) [4, $35,63,65,66]$. Among a total of 287 patients with no N20 SSEP wave at $\leq 72 \mathrm{~h}$ from ROSC, there was only one false positive result [67] [positive predictive value 99.7 (98-100) \%].

In TH-treated patients, a bilaterally absent N20 wave accurately predicts poor outcome both during TH [FPR 0 $(0-2) \%$ ] and after rewarming (at $72 \mathrm{~h}$ from ROSC) [FPR $0.4(0-2) \%$ ], even if two isolated cases of false positive prediction have been reported [68, 69]. In the largest observational study on SSEP in TH-treated patients [38], three patients with a bilaterally absent N20 during TH rapidly recovered consciousness after rewarming and ultimately had a good outcome. In a post hoc assessment, two experienced neurophysiologists reviewed blindly the original tracings and concluded that the SSEP recordings were undeterminable because of excessive noise. Correction of the results after this reassessment led to a FPR of $0(0-3) \%$.

Interobserver agreement for SSEPs in anoxic-ischaemic coma is moderate to good but is influenced by noise [70, 71].

In most prognostication studies, absence of the N20 wave after rewarming has been used-alone or in combination - as a criterion for deciding on WLST, with a consequent risk of self-fulfilling prophecy (see ESM Appendix 3b). SSEP results are more likely to influence physicians' and families' WLST decisions than those of clinical examination or EEG [72].

\subsection{Recommendations}

We recommend:

- Using bilateral absence of N20 SSEP wave at $\geq 72 \mathrm{~h}$ from ROSC to predict poor outcome in comatose survivors from cardiac arrest treated with controlled temperature.

We suggest:

- Using SSEP at $\geq 24 \mathrm{~h}$ after ROSC to predict poor outcome in comatose survivors from cardiac arrest not treated with controlled temperature.

SSEP recording requires appropriate skills and experience, and utmost care should be taken to avoid electrical interference from muscle artefacts or from the ICU environment.

\subsection{Knowledge gaps}

- Most of prognostic accuracy studies on SSEPs in postanoxic coma were not blinded, which may have led to an overestimation of the SSEP prognostic accuracy due to a self-fulfilling prophecy. Blinded studies will be needed to assess the relevance of this bias.

\section{Electroencephalogram (EEG)}

\subsection{Evidence (ESM Table 2)}

\subsubsection{Absence of EEG reactivity}

In TH-treated patients, absence of EEG background reactivity during $\mathrm{TH}$ is almost invariably associated with poor outcome [FPR $2(1-7) \%$; [21, 44, 50]] while, after rewarming at $48-72 \mathrm{~h}$ from ROSC, it predicts a poor outcome with 0 (0-3) \% FPR [42, 44, 50]. However, in one study in posthypoxic myoclonus [48], three patients with no EEG reactivity after rewarming from $\mathrm{TH}$ had a good outcome. Among four prognostication studies on absent EEG reactivity after cardiac arrest included in this document, three $[21,42,44]$ were made by the same group of investigators. Limitations of EEG reactivity include being operator-dependent and non-quantitative, and lacking standardization. Techniques for automated analysis of EEG background reactivity are under investigation [73].

\subsubsection{Status epilepticus}

In TH-treated patients, the presence of status epilepticus (SE), i.e., a prolonged epileptiform activity, during TH or immediately after rewarming [51, 54, 74] is almost invariably followed by poor outcome (FPR from 0 to $6 \%$ ). Among those patients, absence of EEG reactivity $[51,75]$ or a discontinuous EEG background [76] predicted no chance of neurological recovery. All studies on 
SE included only a few patients. Definitions of SE were inconsistent among those studies (see ESM Appendix 5).

\subsubsection{Low voltage EEG}

According to recent guidelines [77], the voltage of background EEG is defined as low when most or all activity is $<20 \mu \mathrm{V}$ (measured from peak to trough) in longitudinal bipolar with standard 10-20 electrodes, while suppression is defined as all voltage being $<10 \mu \mathrm{V}$.

In two studies $[35,67]$ in non-TH-treated patients, a low-voltage EEG $(\leq 20-21 \mu \mathrm{V})$ at $1-3$ days after ROSC predicted poor outcome with 0 [0-6] \% FPR. In one of these studies [35], however, the presence of this EEG pattern was used as a criterion for WLST.

In two studies $[76,78]$ in TH-treated patients, a flat or low-voltage tracing on continuous EEG recorded during $\mathrm{TH}$ or immediately after rewarming was inconsistently associated to a poor outcome (FPR from 0 to $6 \%$ ). In two studies $[79,80]$, a bispectral index (BIS) value of 6 or less recorded during $\mathrm{TH}$, corresponding to a flat or lowamplitude EEG, predicted poor outcome with 0 (0-6) \% FPR, while higher BIS values were less specific [81]. However, in a subsequent study [82], a BIS $\leq 6$ was not $100 \%$ reliable (FPR $17 \%$ [7-32]). There is limited evidence $[76,82]$ on the predictive value of low EEG voltage after rewarming from $\mathrm{TH}$.

Amplitude of the EEG signal may depend on the effect of drugs, body temperature, and on a variety of technical conditions such as skin and scalp impedance, inter-electrode distances, size, type and placement of the exploring electrodes, and type of filters adopted, as well as patientspecific issues [83].

\subsubsection{Burst-suppression}

According to a recent definition [77], burst-suppression is defined as more than $50 \%$ of the EEG record consisting of periods of EEG voltage $<10 \mu \mathrm{V}$, with alternating bursts. In comatose survivors of cardiac arrest, either TH-treated or non-TH-treated, burst-suppression is usually a transient finding. During the first 24-48 h after ROSC [67] in non-TH-treated patients or during TH [44, 78, 84], burst-suppression is common and it may be compatible with neurological recovery, while at $\geq 72 \mathrm{~h}$ from $\operatorname{ROSC}[35,76,85]$ a persisting burst-suppression pattern is less common, but is consistently associated with poor outcome. In one case [61], a good recovery was reported despite an EEG burst-suppression pattern recorded at $72 \mathrm{~h}$ from ROSC; in that case, EEG reactivity was maintained. Definitions of burst-suppression were inconsistent among prognostication studies (see ESM Appendix 6).

\subsection{Recommendations}

We suggest:

- Using EEG-based predictors such as absence of EEG reactivity to external stimuli, presence of burst-suppression or status epilepticus at $\geq 72 \mathrm{~h}$ after ROSC to predict poor outcome in comatose survivors from cardiac arrest.

- Using these predictors only in combination (i.e. presence of burst-suppression or status epilepticus plus an unreactive background) and combining them with other predictors, since these criteria lack standardisation and the relevant evidence is limited to a few studies performed by experienced electrophysiologists.

- Not using a low EEG voltage to predict outcome in comatose survivors of cardiac arrest, because of the limited evidence and the risk of interference from hypothermia, ongoing sedation and technical factors.

We recommend not using burst-suppression for prognostication during the first 24-36 h after ROSC or during $\mathrm{TH}$ in comatose survivors of cardiac arrest.

Apart from its prognostic significance, recording of EEG-either continuous or intermittent-in comatose survivors of cardiac arrest both during $\mathrm{TH}$ and after rewarming is helpful to assess the level of consciousness-which may be masked by prolonged sedation, neuromuscular dysfunction or myoclonus - and to detect and treat non-convulsive seizures [8], which may occur in about one-quarter of comatose survivors of cardiac arrest $[54,76,86]$.

\subsection{Knowledge gaps}

- Larger prospective studies on the prevalence and the predictive value of EEG changes in comatose survivors of cardiac arrest are needed, especially in patients who have been rewarmed from controlled temperature.

- The definition of SE and the modalities for eliciting and evaluating EEG reactivity need standardisation. In future studies, definitions of burst suppression and low-voltage EEG should comply with recent recommendations [77].

- It is not clear whether postanoxic SE is only a marker of brain injury or whether it contributes directly to neurological injury, nor if anti-epileptic treatments may potentially improve its outcome.

\section{Biomarkers}

NSE and S-100B are protein biomarkers that are released following injury to neurons and glial cells, respectively. 
Blood values of NSE or S-100B after cardiac arrest are likely to correlate with the extent of anoxic-ischaemic neurological injury from cardiac arrest and, therefore, with the severity of neurological outcome.

Advantages of biomarkers over both EEG and clinical examination include quantitative results and likely independence from the effects of sedatives. Their main limitation as prognosticators is that it is difficult to find a consistent threshold for identifying patients destined to a poor outcome with a high degree of certainty. In fact, serum concentrations of biomarkers are per se continuous variables, which limits their applicability for predicting a dichotomous outcome, especially when a threshold for $0 \%$ FPR is required.

\subsection{Evidence (ESM Table 3)}

\subsubsection{Neuron-specific enolase (NSE)}

In non-TH-treated patients, the 2006 AAN review [2] identified an NSE threshold of $33 \mu \mathrm{g} \mathrm{L}^{-1}$ at days 1-3 from ROSC as an accurate predictor of poor outcome with $0 \%$ FPR. However, in a study [4] included in that review, this threshold was $47.6 \mu \mathrm{g} \mathrm{L}^{-1}$ at $24 \mathrm{~h}$, while, in a large cohort study [5] published after the AAN review, this threshold was $65.0 \mu \mathrm{g} \mathrm{L}^{-1}$ at $48 \mathrm{~h}$ and $80 \mu \mathrm{g} \mathrm{L}^{-1}$ at $72 \mathrm{~h}$. In three other studies [3,63,87], values of NSE between 65 and $85 \mu \mathrm{g} \mathrm{L}^{-1}$ at 3-5 days were reported as compatible with recovery of consciousness.

In TH-treated patients, the threshold for $0 \%$ FPR varied between 38.1 and $80.8 \mu \mathrm{g} \mathrm{L}^{-1}$ at $24 \mathrm{~h}[20,74,88$ 90], between 25 and $151.5 \mu \mathrm{g} \mathrm{L}-1$ at $48 \mathrm{~h}[20,22,38,74$, 88-93], and between 27.3 and $78.9 \mu \mathrm{g} \mathrm{L}^{-1}$ at $72 \mathrm{~h}$ [6, 90, 91]. However, the distribution of NSE values in available studies $[5,6,22,38,88,91]$ indicates that NSE values above $60 \mu \mathrm{g} \mathrm{L}^{-1}$ at $48-72 \mathrm{~h}$ from ROSC are very rarely associated with good outcome. Limited evidence [20, 89, 94] suggests that the discriminative value of NSE levels at $48-72 \mathrm{~h}$ is higher than at $24 \mathrm{~h}$.

\subsubsection{S-100B}

S-100B is less well documented than is NSE. As for NSE, inconsistencies were found in its thresholds for $0 \%$ FPR. In non-TH-treated patients, these thresholds ranged from 0.19 to $5.2 \mu \mathrm{g} \mathrm{L}^{-1}$ at $24 \mathrm{~h}[4,92,95]$ and from 0.12 to $0.25 \mu \mathrm{g} \mathrm{L}^{-1}$ at $48 \mathrm{~h}[92,96,97]$. Precision was very low in all studies.

In TH-treated patients, the thresholds for a $0 \%$ FPR ranged from 0.18 to $1.15 \mu \mathrm{g} \mathrm{L}^{-1}$ at $24 \mathrm{~h}$ after ROSC [90, $92,98]$, and from 0.30 to $2.15 \mu \mathrm{g} \mathrm{L}^{-1}$ at $48 \mathrm{~h}[82,90]$. Finally, in one study [90], the threshold for $0 \%$ FPR at $72 \mathrm{~h}$ was $0.92 \mu \mathrm{g} \mathrm{L}^{-1}$.
The main reasons for the observed variability in biomarker thresholds may include the use of heterogeneous measurement techniques $[99,100]$, the presence of extraneuronal sources of biomarkers (haemolysis and neuroendocrine tumours for NSE [101], muscle and adipose tissue breakdown for S-100B [102]), and the incomplete knowledge of the kinetics of their blood concentrations in the first few days after ROSC. Some evidence [89, 90, 94] suggests that not only the biomarkers' absolute concentrations but also their trends over time may have predictive value.

\subsection{Recommendations}

We suggest:

- Using high serum values of NSE at 48-72 h from ROSC in combination with other predictors for prognosticating a poor neurological outcome in comatose survivors from cardiac arrest, either TH-treated or nonTH-treated. However, no threshold enabling prediction with zero FPR can be recommended.

- Using utmost care and preferably sampling at multiple time points when assessing NSE to avoid false positive results due to haemolysis.

\subsection{Knowledge gaps}

- There is a need for standardisation of the measuring techniques for NSE and S-100 in cardiac arrest patients.

- Little information is available on the kinetics of the blood concentrations of biomarkers in the first few days after cardiac arrest.

\section{Imaging}

\subsection{Evidence (ESM Table 4)}

\subsubsection{Brain $C T$}

Brain CT is often performed in resuscitated comatose patients, mainly to exclude further causes of coma, such as subarachnoid haemorrhage [103]. The main CT finding of global anoxic-ischaemic cerebral insult following cardiac arrest is cerebral oedema [104], which appears as a reduction in the depth of cerebral sulci (sulcal effacement) and an attenuation of the grey matter/white matter (GM/WM) interface, due to a decreased density of the GM. In one study [105], the presence of this pattern on brain CT performed immediately after resuscitation predicted poor outcome with $81 \%$ sensitivity and 8 (0-38) \% FPR. The attenuation of the GM/WM interface has been quantitatively measured as the ratio (GWR) 
between the GM and the WM densities. The GWR threshold below which poor outcome was predicted with $0 \%$ FPR ranged between 1.12 and 1.22 [20, 33, 106]. The methods for GWR calculation were inconsistent among studies.

\subsubsection{MRI}

Advantages of MRI over brain CT include a better spatial definition and a high sensitivity for identifying ischaemic brain injury; however, its use can be problematic in the most clinically unstable patients [107].

The earliest post-ischaemic MRI change is hyperintensity in cortical areas or basal ganglia on diffusion weighted imaging (DWI) sequences. In two small studies $[108,109]$, the presence of large multilobar changes on DWI or FLAIR MRI sequences performed within 5 days from ROSC was consistently associated with death or vegetative state while focal or small volume lesions were not [93]. In patients with poor outcome after resuscitation from cardiac arrest, MRI can reveal extensive changes when results of other predictors such as SSEP or ocular reflexes are normal $[93,107]$.

Apparent diffusion coefficient (ADC) is a quantitative measure of ischaemic DWI changes. ADC values between 700 and $800 \times 10^{-6} \mathrm{~mm}^{2} / \mathrm{s}$ are considered to be normal [107]. Several methods have been used to quantify the DWI changes following cardiac arrest in order to predict outcome. Measured parameters include whole-brain ADC [110], the proportion of brain volume with low ADC [111] and the lowest ADC value in specific brain areas, such as the cortical occipital area and the putamen [88, 112]. The ADC thresholds associated with $0 \%$ FPR vary among studies. These methods depend partly on subjective human decision in identifying the region of interest to be studied and in the interpretation of results, although automated analysis has recently been proposed [19]. According to one study [109], the optimal time window for prognostication based on ADC is 3-5 days from ROSC in the cortical structures and 6-8 days in the subcortical structures. Both the timing and severity of MRI changes after arrest differ between cortical areas.

Advanced MRI techniques, such as fractional anisotropy [113] and axial diffusivity in diffusion-tensor (DT) imaging [114], have recently been tested in humans to evaluate the white matter disorganisation and the axonal damage following diffuse anoxic-ischemic brain injury, respectively. Limited evidence shows that these techniques may be useful to predict outcome in patients who are persistently comatose after cardiac arrest and that their accuracy is comparable or superior to that of ADC [113].

All studies on prognostication after cardiac arrest using imaging have a small sample size with a consequent low precision, and a very low quality of evidence. Most of those studies are retrospective, and brain CT or MRI had been made at discretion of the treating physician, which may have caused a selection bias and overestimated their performance.

\subsection{Recommendations}

We suggest:

- Using the presence of a marked reduction of the GM/ WM ratio or sulcal effacement on brain CT within $24 \mathrm{~h}$ after ROSC, or the presence of extensive reduction in diffusion on brain MRI at 2-5 days after ROSC, to predict a poor outcome in patients who are comatose after resuscitation from cardiac arrest both $\mathrm{TH}$-treated or non-TH-treated.

- Using brain CT and MRI for prognosticating poor outcome after cardiac arrest only in combination with other predictors.

- Using brain imaging studies for prognostication only in centres where specific experience is available, given the limited number of studied patients, the spatial and temporal variability of post-anoxic changes in both CT and MRI, and the lack of standardisation for quantitative measures of these changes.

\subsection{Knowledge gaps}

- Evidence on imaging studies in comatose survivors of cardiac arrest is limited by small sample size and likely selection bias. Larger prospective studies are needed to confirm the results of the currently available studies.

- The severity of brain CT and MRI changes after global ischaemic injury will need a standardised description, e.g. using scoring systems similar to those used for traumatic brain injury [115].

- The prognostic value of quantitative vector indices derived from DT imaging, such as fractional anisotropy and axial diffusivity, need to be evaluated in future studies.

\section{Self-fulfilling prophecy}

Almost all prognostication studies reviewed in this document were assigned a low or very low quality of evidence (see Evidence Profile Tables on ESM Appendix $3 a-d)$ the main reason being the risk of self-fulfilling prophecy. In fact, only $9 / 73$ studies $(12 \%)-3$ of which are from the same group-reported blinding of the treating team from the results of the predictor under investigation. In 2 of these studies [37, 38], results of the predictor (absence of N20 SSEP wave) recorded during 
$\mathrm{TH}$ were not disclosed, but if patients remained comatose after rewarming, a second SSEP was performed and results were disclosed to the treating team, who used this information for treatment decisions. A treatment suspension policy was reported in 37/73 studies (51\%), although only 27 of those studies described the criteria for WLST. In 14/37 studies (38 \%), the treatment suspension policy was based, at least in part, on one or more of the predictors under investigation (see ESM Table 5). Treatment limitations were applied at a minimum of 3 days or less from cardiac arrest in 12 studies and from 3 to 7 days in 9 studies, while in the remaining studies the minimal duration of life support measures was not reported.

Prevention of self-fulfilling prophecy bias would require blinding of test results to the treating team and providing sufficiently prolonged life support in patients who do not recover consciousness after resuscitation and rewarming. Both those tasks are difficult to accomplish. Some predictors, such as results of clinical examination, cannot be concealed to the treating team. Others, such as EEG, should not be concealed as they can reveal the presence of potentially treatable complications, like seizures. In some institutions, having a dedicated investigator not involved in patient management who will ensure blinding of collected data may not be feasible [80]. On the other hand, indefinite supportive care in potentially hopeless patients raises both ethical and financial concerns. However, even when the risk of self-fulfilling prophecy cannot be avoided in order to adequately account for this bias, it is desirable that future prognostic accuracy studies report in detail the criteria for withdrawal or limitation of life-sustaining treatment, as has been done in recent trials [116].

\section{Practical approach: suggested prognostication strategy}

Prognostication is indicated in patients with prolonged coma after resuscitation. A thorough clinical examination should be performed daily to detect signs of neurological recovery such as purposeful movements or to identify a clinical picture suggesting that brain death has occurred.

Following global post-anoxic injury, the brain will make a gradual recovery. Brainstem reflexes return first, then the motor response to pain and, finally, cortical activity and consciousness [117]. This process is completed within $72 \mathrm{~h}$ from arrest $[53,117]$. Consequently, in the absence of residual sedation, $72 \mathrm{~h}$ after ROSC seems to be a suitable time for prognostication. However, in patients who have received sedatives $\leq 12 \mathrm{~h}$ before the $72 \mathrm{~h}$ neurological assessment, the reliability of clinical examination may be reduced [3]. Special care must be taken in TH-treated patients, since hypothermia prolongs the effects of both opiates [118] and neuromuscular blocking drugs $[119,120]$.

Before decisive assessment is performed, major confounders must be excluded [121, 122]; apart from sedation and neuromuscular blockade, these include hypothermia, severe hypotension, hypoglycaemia, and metabolic and respiratory derangements. Sedatives and neuromuscular blocking drugs should be suspended long enough to avoid interference with clinical examination. Short-acting drugs are preferred whenever possible. When residual sedation/paralysis is suspected, consider using antidotes to reverse the effects of these drugs. Be careful if using flumazenil to reverse the effects of benzodiazepines, since this drug may lower the seizure threshold.

We suggest using the prognostication strategy outlined in the algorithm on Fig. 1 in all comatose patients with an absent or extensor motor response to pain at $\geq 72 \mathrm{~h}$ from ROSC. Results of earlier prognostic tests should also be considered at this time point.

Evaluate the most robust predictors first. These predictors have the highest specificity and precision (FPR $<5 \%$ with $95 \%$ CIs $<5 \%$ in patients treated with controlled temperature) and have been documented in $>5$ studies from at least three different groups of investigators. They include bilaterally absent pupillary reflexes at $\geq 72 \mathrm{~h}$ from ROSC and bilaterally absent SSEP N20 wave after rewarming (this last sign can be evaluated at $\geq 24 \mathrm{~h}$ from ROSC in patients who have not been treated with controlled temperature). Based on exert opinion, we suggest combining the absence of pupillary reflexes with those of corneal reflexes for predicting poor outcome at this time point. Both these predictors maintain their predictive value irrespective of hypothermia treatment [18].

If none of the signs above is present, a group of less accurate predictors can be evaluated, but the degree of confidence in their prediction will be lower. These have FPR $<5 \%$ but wider $95 \%$ CIs than the previous predictors, and/or their definition/threshold is inconsistent in prognostication studies. These predictors include the presence of early status myoclonus (within $48 \mathrm{~h}$ from ROSC), high values of serum NSE at 48-72 h after ROSC, an unreactive malignant EEG pattern (burst-suppression, status epilepticus) after rewarming, the presence of a marked reduction of the GM/WM ratio or sulcal effacement on brain CT within $24 \mathrm{~h}$ after ROSC or the presence of diffuse ischemic changes on brain MRI at 2-5 days after ROSC. Based on expert opinion, we suggest waiting at least $24 \mathrm{~h}$ after the first prognostication assessment and confirming unconsciousness with M1-2 before using this second set of predictors. We also suggest combining at least two of these predictors for prognostication.

No specific NSE threshold for prediction of poor outcome with $0 \%$ FPR can be recommended at present, although, in all the studies we analysed, NSE values 


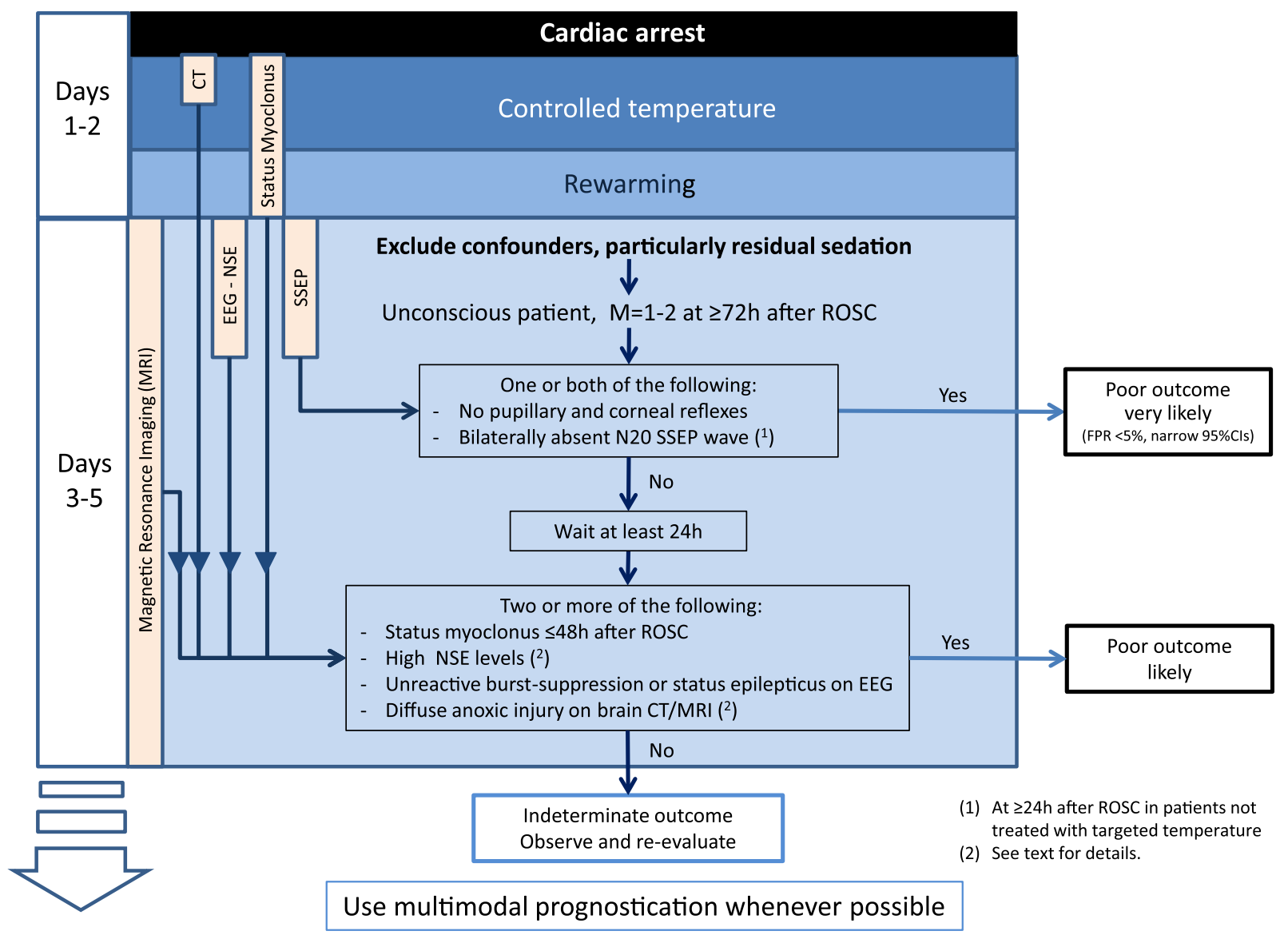

Fig. 1 Suggested prognostication algorithm. The algorithm is entered $\geq 72 \mathrm{~h}$ after ROSC if, after the exclusion of confounders (particularly residual sedation), the patient remains unconscious with a Glasgow Motor Score of 1 or 2 . The absence of pupillary and corneal reflexes, and/or bilaterally absent N20 SSEP wave, indicates a poor outcome is very likely. If neither of the features

greater than $60 \mu \mathrm{g} \mathrm{L}^{-1}$ at $48-72 \mathrm{~h}$ were very rarely associated with a false positive prediction. Ideally, every laboratory hospital assessing NSE should create its own normal values and cut-off levels based on the test kit used. Care should be taken to avoid haemolysis when sampling NSE.

Although the most robust predictors showed no false positives in most studies, none of them singularly predicts poor outcome with absolute certainty when the relevant comprehensive evidence is considered. Moreover, those predictors have often been used for WLST decisions, with the risk of a self-fulfilling prophecy. For this reason, we recommend that prognostication should be multimodal whenever possible, even in the presence of one of these predictors. Apart from increasing safety, limited evidence [20, 21, 42, is present, wait at least $24 \mathrm{~h}$ before reassessing. At this stage, two or more of the following indicate that a poor outcome is likely: status myoclonus $\leq 48 \mathrm{~h}$; high neuron-specific enolase values; unreactive EEG with burst suppression or status epilepticus; diffuse anoxic injury on brain CT and/or MRI. If none of these criteria are met consider continue to observe and re-evaluate

82] also suggests that multimodal prognostication increases sensitivity.

When prolonged sedation and/or paralysis is necessary, for example because of the need to treat severe respiratory insufficiency, we recommend postponing prognostication until a reliable clinical examination can be performed. Biomarkers, SSEP and imaging studies may play a role in this context, since they are insensitive to drug interference.

When dealing with an uncertain outcome, clinicians should consider prolonged observation. Absence of clinical improvement over time suggests a worse outcome. Although awakening has been described as late as 25 days after arrest [54, 61, 123], most survivors will recover consciousness within 1 week [93, 124-126]. In a recent observational study [126], $94 \%$ of patients awoke 
within 4.5 days from rewarming and the remaining $6 \%$ awoke within 10 days.

\section{Conclusions}

A careful clinical neurological examination remains the foundation for prognostication of the comatose patient after cardiac arrest [127]. Adequate time should be given initially for the early awakeners to regain consciousness and to avoid interference from residual effects of sedatives and/or neuromuscular blocking drugs. This implies waiting until $72 \mathrm{~h}$ or more after ROSC before predicting poor outcome, although some indicators can be evaluated earlier. Whenever possible, prognosticate using multiple predictors, depending on locally available tests and expertise. If the results of prognostic tests produce conflicting results or prognostication is uncertain, we recommend further clinical observation and reevaluation.

Author contributions Evidence evaluation: Alain $\mathrm{Ca}-$ riou, Fabio Cavallaro, Tobias Cronberg, Hans Friberg, Cornelia Hoedemaekers, Janneke Horn, Jerry Nolan, Andrea Rossetti, Jasmeet Soar, Claudio Sandroni

Drafting of the manuscript: Claudio Sandroni, Jerry Nolan (Manuscript's body text and Figure); Fabio Cavallaro, Tobias Cronberg (Tables)

Revision of the manuscript: Alain Cariou, Hans Friberg, Cornelia Hoedemaekers, Janneke Horn, Andrea Rossetti, Jasmeet Soar

Data search and analysis: Fabio Cavallaro, Claudio Sandroni

\section{Conflict of interest}

- Claudio Sandroni is a member of the Editorial Board of the journal Resuscitation (unpaid); evidence reviewer of the Advanced Life Support Task Force, International Liaison Committee on Resuscitation (ILCOR) (unpaid). $\mathrm{He}$ is the first author of two systematic reviews on prognostication in comatose patients resuscitated from cardiac arrest.

- Alain Cariou is the Deputy of Trauma and Emergency Medicine (TEM) Section of the European Society of Intensive Care Medicine (ESICM) and Delegate from the ESICM in the General Assembly of the European Resuscitation Council (ERC). He received academic research grants from the French Ministry of Health for conducting clinical research in the field of cardiac arrest (all data controlled by the investigators).
- Fabio Cavallaro is a co-author of two systematic reviews on prognostication in comatose patients resuscitated from cardiac arrest.

- Tobias Cronberg is the Coordinator of recommendations on prognostication after cardiac arrest, Swedish Resuscitation Council. He received academic research grants from multiple non-profit organisations for the conduct of a cognitive sub-study and EEG sub-study of the Target Temperature Management trial (all data controlled by the investigators).

- Hans Friberg received lecture fees from Natus, Inc. (manufacturer of NervusMonitor, cont. EEG/aEEG) and from Bard Medical. He received grants from the EU Interreg. Programme IV A and academic research grants from multiple non-profit organisations for the Target Temperature Management trial (all data controlled by the investigators). He is the chair of the working party "Care after cardiac arrest", Swedish Resuscitation Council.

- Cornelia Hoedemaekers is co-author of a systematic review on diagnostic tools for prediction of poor outcome after cardiopulmonary resuscitation.

- Janneke Horn received a grant from the Dutch Heart Foundation (2007B039) for the PROPAC II study and from the Dutch Brain Foundation (14F06.48) for research on SSEP during hypothermia treatment after cardiac arrest (data controlled by the investigator and no restrictions on publication). She is the principal investigator of the PROPACII study and co-author of a systematic review on diagnostic tools for prediction of poor outcome after cardiopulmonary resuscitation.

- Jerry Nolan is the Editor-in-Chief of Resuscitation and Vice-Chair, European Resuscitation Council.

- Andrea Rossetti received a grant from the Swiss National Science Foundation (grant no. CR32I3_143780).

- Jasmeet Soar is the Editor of Resuscitation (Honorarium). He is member of the Executive Committee, Resuscitation Council (UK) (unpaid); Chair of the ERC ALS Working Group (unpaid); and Co-chair of the ALS ILCOR Task Force (unpaid).

Acknowledgments We gratefully thank Drs. Simona Gaudino, MD, neuroradiologist, and Erik Westhall, MD, neurophysiologist, for their advice.

Open Access This article is distributed under the terms of the Creative Commons Attribution NonCommercial NoDerivatives 4.0 International License which permits re-use and distribution of the article (in whole or in part) for non-commercial purposes in any medium or format provided that inter alia the original author(s) and the source are credited. The license does neither allow the use of the article for commercial purposes (for example the distribution of the article via commercial channels) nor the distribution of modified versions of the article. 


\section{References}

1. Stiell IG, Nichol G, Leroux BG, Rea TD, Ornato JP, Powell J, Christenson J, Callaway CW, Kudenchuk PJ, Aufderheide TP, Idris AH, Daya MR, Wang HE, Morrison LJ, Davis D, Andrusiek D, Stephens S, Cheskes S, Schmicker RH, Fowler R,

Vaillancourt C, Hostler D, Zive D, Pirrallo RG, Vilke GM, Sopko G, Weisfeldt M (2011) Early versus later rhythm analysis in patients with outof-hospital cardiac arrest. N Engl J Med 365:787-797

2. Wijdicks EF, Hijdra A, Young GB, Bassetti CL, Wiebe S (2006) Practice parameter: prediction of outcome in comatose survivors after cardiopulmonary resuscitation (an evidence-based review): report of the Quality Standards Subcommittee of the American Academy of Neurology. Neurology 67:203-210

3. Samaniego EA, Mlynash M, Caulfield AF, Eyngorn I, Wijman CA (2011) Sedation confounds outcome prediction in cardiac arrest survivors treated with hypothermia. Neurocrit Care 15:113-119

4. Zingler VC, Krumm B, Bertsch T, Fassbender K, Pohlmann-Eden B (2003) Early prediction of neurological outcome after cardiopulmonary resuscitation: a multimodal approach combining neurobiochemical and electrophysiological investigations may provide high prognostic certainty in patients after cardiac arrest. Eur neurol 49:79-84

5. Reisinger J, Hollinger $\mathrm{K}$, Lang W, Steiner C, Winter T, Zeindlhofer E, Mori M, Schiller A, Lindorfer A, Wiesinger K, Siostrzonek P (2007) Prediction of neurological outcome after cardiopulmonary resuscitation by serial determination of serum neuronspecific enolase. Eur Heart J 28:52-58

6. Steffen IG, Hasper D, Ploner CJ, Schefold JC, Dietz E, Martens F, Nee J, Krueger A, Jorres A, Storm C (2010) Mild therapeutic hypothermia alters neuron specific enolase as an outcome predictor after resuscitation: 97 prospective hypothermia patients compared to 133 historical nonhypothermia patients. Crit Care 14:R69

7. Sandroni C, Cavallaro F, Callaway CW, Sanna T, D'Arrigo S, Kuiper M, Della Marca G, Nolan JP (2013) Predictors of poor neurological outcome in adult comatose survivors of cardiac arrest: a systematic review and meta-analysis. Part 1: patients not treated with therapeutic hypothermia. Resuscitation 84:1310-1323
8. Claassen J, Taccone FS, Horn P, Holtkamp M, Stocchetti N, Oddo M (2013) Recommendations on the use of EEG monitoring in critically ill patients: consensus statement from the neurointensive care section of the ESICM. Intensive Care Med 39:1337-1351

9. Geocadin RG, Peberdy MA, Lazar RM (2012) Poor survival after cardiac arrest resuscitation: a self-fulfilling prophecy or biologic destiny? Crit Care Med 40:979-980

10. World Health Organization (2003) Global programme on evidence for health policy. Guidelines for WHO guidelines. EIP/GPE/EQC/2003; 2003

11. European society of intensive care medicine standard operating procedures (SOPs) for manuscript endorsement process. Available on http://www.esicm.org/publication/ endorsed. Last accessed May 29, 2014

12. Sandroni C, Cavallaro F, Callaway CW, D'Arrigo S, Sanna T, Kuiper MA, Biancone M, Della Marca G, Farcomeni A, Nolan JP (2013) Predictors of poor neurological outcome in adult comatose survivors of cardiac arrest: a systematic review and meta-analysis. Part 2: patients treated with therapeutic hypothermia. Resuscitation 84:1324-1338

13. Teasdale G, Jennett B (1974) Assessment of coma and impaired consciousness. Pract Scale Lancet 2:81-84

14. Brain Resuscitation Clinical Trial I Study Group (1986) Randomized clinical study of thiopental loading in comatose survivors of cardiac arrest. N Engl J Med 314:397-403

15. Newcommon NJ, Green TL, Haley E, Cooke T, Hill MD (2003) Improving the assessment of outcomes in stroke: use of a structured interview to assign grades on the modified Rankin Scale. Stroke 34:377-378 author reply 377-378

16. Becker LB, Aufderheide TP, Geocadin RG, Callaway CW, Lazar RM, Donnino MW, Nadkarni VM, Abella BS, Adrie C, Berg RA, Merchant RM, O'Connor RE, Meltzer DO, Holm MB, Longstreth WT, Halperin HR, American Heart Association Emergency Cardiovascular Care C, Council on Cardiopulmonary CCP, Resuscitation (2011) Primary outcomes for resuscitation science studies: a consensus statement from the American Heart Association. Circulation 124:2158-2177
17. Kamps MJ, Horn J, Oddo M, Fugate JE, Storm C, Cronberg T, Wijman CA, Wu O, Binnekade JM, Hoedemaekers CW (2013) Prognostication of neurologic outcome in cardiac arrest patients after mild therapeutic hypothermia: a meta-analysis of the current literature. Intensive Care Med 39:1671-1682

18. Greer DM, Yang J, Scripko PD, Sims JR, Cash S, Wu O, Hafler JP, Schoenfeld DA, Furie KL (2013) Clinical examination for prognostication in comatose cardiac arrest patients. Resuscitation 84:1546-1551

19. Kim J, Kim K, Hong S, Kwon B, Yun ID, Choi BS, Jung C, Lee JH, Jo YH, Kim T, Rhee JE, Lee SH (2013) Low apparent diffusion coefficient clusterbased analysis of diffusion-weighted MRI for prognostication of out-ofhospital cardiac arrest survivors. Resuscitation 84:1393-1399

20. Lee BK, Jeung KW, Lee HY, Jung YH, Lee DH (2013) Combining brain computed tomography and serum neuron specific enolase improves the prognostic performance compared to either alone in comatose cardiac arrest survivors treated with therapeutic hypothermia. Resuscitation 84:1387-1392

21. Oddo M, Rossetti AO (2014) Early multimodal outcome prediction after cardiac arrest in patients treated with hypothermia. Crit Care Med 42:1340-1347

22. Zellner T, Gartner R, Schopohl J, Angstwurm M (2013) NSE and S-100B are not sufficiently predictive of neurologic outcome after therapeutic hypothermia for cardiac arrest. Resuscitation 84:1382-1386

23. Schunemann HJ, Oxman AD, Brozek J, Glasziou P, Jaeschke R, Vist GE, Williams JW Jr, Kunz R, Craig J, Montori VM, Bossuyt P, Guyatt GH, Group GW (2008) Grading quality of evidence and strength of recommendations for diagnostic tests and strategies. Br Med $\mathbf{J}$ 336:1106-1110

24. Andrews J, Guyatt G, Oxman AD, Alderson P, Dahm P, Falck-Ytter Y, Nasser M, Meerpohl J, Post PN, Kunz R, Brozek J, Vist G, Rind D, Akl EA, Schunemann HJ (2013) GRADE guidelines: 14. Going from evidence to recommendations: the significance and presentation of recommendations. J Clin Epidemiol 66:719-725 
25. Andrews JC, Schunemann HJ, Oxman AD, Pottie K, Meerpohl JJ, Coello PA, Rind D, Montori VM, Brito JP, Norris S, Elbarbary M, Post P, Nasser M, Shukla V, Jaeschke R, Brozek J, Djulbegovic B, Guyatt G (2013) GRADE guidelines: 15. Going from evidence to recommendationdeterminants of a recommendation's direction and strength. J Clin Epidemiol 66:726-735

26. Balshem H, Helfand M, Schunemann HJ, Oxman AD, Kunz R, Brozek J, Vist GE, Falck-Ytter Y, Meerpohl J, Norris S, Guyatt GH (2011) GRADE guidelines: 3. Rating the quality of evidence. J Clin Epidemiol 64:401-406

27. Guyatt G, Oxman AD, Akl EA, Kunz $\mathrm{R}$, Vist G, Brozek J, Norris S, FalckYtter Y, Glasziou P, DeBeer H, Jaeschke R, Rind D, Meerpohl J, Dahm P, Schunemann HJ (2011) GRADE guidelines: 1. IntroductionGRADE evidence profiles and summary of findings tables. J Clin Epidemiol 64:383-394

28. Hsu J, Brozek JL, Terracciano L, Kreis J, Compalati E, Stein AT, Fiocchi A, Schunemann HJ (2011) Application of GRADE: making evidence-based recommendations about diagnostic tests in clinical practice guidelines. Implementation Sci; $6: 62$

29. Rifai N, Altman DG, Bossuyt PM (2008) Reporting bias in diagnostic and prognostic studies: time for action. Clinical Chem 54:1101-1103

30. Blyth CR (1986) Approximate binomial confidence limits. J Am Stat Assoc 81:843-855

31. Earnest MP, Breckinridge JC, Yarnell PR, Oliva PB (1979) Quality of survival after out-of-hospital cardiac arrest: predictive value of early neurologic evaluation. Neurology 29:56-60

32. Okada K, Ohde S, Otani N, Sera T, Mochizuki T, Aoki M, Ishimatsu S (2012) Prediction protocol for neurological outcome for survivors of out-of-hospital cardiac arrest treated with targeted temperature management. Resuscitation 83:734-739

33. Choi SP, Youn CS, Park KN, Wee JH, Park JH, Oh SH, Kim SH, Kim JY (2012) Therapeutic hypothermia in adult cardiac arrest because of drowning. Acta Anaesthesiol Scand 56:116-123
34. Bertini G, Margheri M, Giglioli C, Cricelli F, De Simone L, Taddei T, Marchionni N, Zini G, Gensini GF (1989) Prognostic significance of early clinical manifestations in postanoxic coma: a retrospective study of 58 patients resuscitated after prehospital cardiac arrest. Crit Care Med 17:627-633

35. Zandbergen EG, Hijdra A, Koelman JH, Hart AA, Vos PE, Verbeek MM, de Haan RJ (2006) Prediction of poor outcome within the first 3 days of postanoxic coma. Neurology 66:62-68

36. Bisschops LL, van Alfen N, Bons S, van der Hoeven JG, Hoedemaekers CW (2011) Predictors of poor neurologic outcome in patients after cardiac arrest treated with hypothermia: a retrospective study. Resuscitation 82:696-701

37. Bouwes A, Binnekade JM, Zandstra DF, Koelman JH, van Schaik IN, Hijdra A, Horn J (2009) Somatosensory evoked potentials during mild hypothermia after cardiopulmonary resuscitation. Neurology 73:1457-1461

38. Bouwes A, Binnekade JM, Kuiper MA, Bosch FH, Zandstra DF, Toornvliet AC, Biemond HS, Kors BM, Koelman JH, Verbeek MM, Weinstein HC, Hijdra A, Horn J (2012) Prognosis of coma after therapeutic hypothermia: a prospective cohort study. Ann Neurol 71:206-212

39. Fugate JE, Wijdicks EF, Mandrekar J, Claassen DO, Manno EM, White RD, Bell MR, Rabinstein AA (2010) Predictors of neurologic outcome in hypothermia after cardiac arrest. Ann Neurol 68:907-914

40. Wu O, Batista LM, Lima FO, Vangel MG, Furie KL, Greer DM (2011)

Predicting clinical outcome in comatose cardiac arrest patients using early noncontrast computed tomography. Stroke 42:985-992

41. Topcuoglu MA, Oguz KK, Buyukserbetci G, Bulut E (2009) Prognostic value of magnetic resonance imaging in postresuscitation encephalopathy. Intern Med 48:1635-1645

42. Rossetti AO, Oddo M, Logroscino G, Kaplan PW (2010) Prognostication after cardiac arrest and hypothermia: a prospective study. Ann Neurol 67:301-307

43. Rossetti AO, Urbano LA, Delodder F, Kaplan PW, Oddo M (2010) Prognostic value of continuous EEG monitoring during therapeutic hypothermia after cardiac arrest. Crit Care 14:R173
44. Rossetti AO, Carrera E, Oddo M (2012) Early EEG correlates of neuronal injury after brain anoxia. Neurology 78:796-802

45. Booth CM, Boone RH, Tomlinson G, Detsky AS (2004) Is this patient dead, vegetative, or severely neurologically impaired? Assessing outcome for comatose survivors of cardiac arrest. J Am Med Assoc 291:870-879

46. Larson MD, Muhiudeen I (1995) Pupillometric analysis of the 'absent light reflex'. Arch Neurol 52:369-372

47. Suys T, Bouzat P, Marques-Vidal P, Sala N, Payen JF, Rossetti AO, Oddo M (2014) Automated quantitative pupillometry for the prognostication of coma after cardiac arrest. Neurocrit Care in press. PMID: 24760270

48. Bouwes A, van Poppelen D, Koelman JH, Kuiper MA, Zandstra DF, Weinstein HC, Tromp SC,

Zandbergen EG, Tijssen MA, Horn J (2012) Acute posthypoxic myoclonus after cardiopulmonary resuscitation. BMC Neurol 12:63

49. Thomke F, Marx JJ, Sauer O, Hundsberger T, Hagele S, Wiechelt J, Weilemann SL (2005) Observations on comatose survivors of cardiopulmonary resuscitation with generalized myoclonus. BMC Neurol 5:14

50. Crepeau AZ, Rabinstein AA, Fugate JE, Mandrekar J, Wijdicks EF, White RD, Britton JW (2013) Continuous EEG in therapeutic hypothermia after cardiac arrest: Prognostic and clinical value. Neurology 80:339-344

51. Legriel S, Hilly-Ginoux J, RescheRigon M, Merceron S, Pinoteau J, Henry-Lagarrigue $\mathrm{M}$, Bruneel $\mathrm{F}$, Nguyen A, Guezennec P, Troche G, Richard O, Pico F, Bedos JP (2013) Prognostic value of electrographic postanoxic status epilepticus in comatose cardiac-arrest survivors in the therapeutic hypothermia era. Resuscitation 84:343-350

52. Krumholz A, Stern BJ, Weiss HD (1988) Outcome from coma after cardiopulmonary resuscitation: relation to seizures and myoclonus. Neurology 38:401-405

53. Wijdicks EF, Young GB (1994) Myoclonus status in comatose patients after cardiac arrest. Lancet 343:1642-1643

54. Rittenberger JC, Popescu A, Brenner RP, Guyette FX, Callaway CW (2012) Frequency and timing of nonconvulsive status epilepticus in comatose post-cardiac arrest subjects treated with hypothermia. Neurocrit Care 16:114-122 
55. Accardo J, De Lisi D, Lazzerini P, Primavera A (2013) Good functional outcome after prolonged postanoxic comatose myoclonic status epilepticus in a patient who had undergone bone marrow transplantation. Rep Neurol Med 2013:872127

56. Arnoldus EP, Lammers GJ (1995) Postanoxic coma: good recovery despite myoclonus status. Ann Neurol 38:697-698

57. Datta S, Hart GK, Opdam H, Gutteridge G, Archer J (2009) Posthypoxic myoclonic status: the prognosis is not always hopeless. Crit Care Resusc 11:39-41

58. English WA, Giffin NJ, Nolan JP (2009) Myoclonus after cardiac arrest: pitfalls in diagnosis and prognosis. Anaesthesia 64:908-911

59. Goh WC, Heath PD, Ellis SJ, Oakley PA (2002) Neurological outcome prediction in a cardiorespiratory arrest survivor. Br J Anaesth 88:719-722

60. Morris HR, Howard RS, Brown P (1998) Early myoclonic status and outcome after cardiorespiratory arrest. J Neurol Neurosurg Psychiatry 64:267-268

61. Greer DM (2013) Unexpected good recovery in a comatose post-cardiac arrest patient with poor prognostic features. Resuscitation 84:e81-e82

62. Lucas JM, Cocchi MN, Salciccioli J, Stanbridge JA, Geocadin RG, Herman ST, Donnino MW (2012) Neurologic recovery after therapeutic hypothermia in patients with post-cardiac arrest myoclonus. Resuscitation 83:265-269

63. Stelzl T, von Bose MJ, Hogl B, Fuchs HH, Flugel KA (1995) A comparison of the prognostic value of neuronspecific enolase serum levels and somatosensory evoked potentials in 13 reanimated patients. Eur J Emerg Med 2:24-27

64. Tiainen M, Kovala TT, Takkunen OS, Roine RO (2005) Somatosensory and brainstem auditory evoked potentials in cardiac arrest patients treated with hypothermia. Crit Care Med 33:1736-1740

65. Rothstein TL (2000) The role of evoked potentials in anoxic-ischemic coma and severe brain trauma. J Clin Neurophysiol 17:486-497

66. Zanatta P, Messerotti Benvenuti S, Baldanzi F, Bosco E (2012) Painrelated middle-latency somatosensory evoked potentials in the prognosis of post anoxic coma: a preliminary report. Minerva Anestesiol 78:749-756
67. Young GB, Doig G, Ragazzoni A (2005) Anoxic-ischemic encephalopathy: clinical and electrophysiological associations with outcome. Neurocrit Care 2:159-164

68. Howell K, Grill E, Klein AM, Straube A, Bender A (2013) Rehabilitation outcome of anoxic-ischaemic encephalopathy survivors with prolonged disorders of consciousness. Resuscitation 84:1409-1415

69. Leithner C, Ploner CJ, Hasper D, Storm C (2010) Does hypothermia influence the predictive value of bilateral absent N20 after cardiac arrest? Neurology 74:965-969

70. Zandbergen EG, Hijdra A, de Haan RJ, van Dijk JG, Ongerboer de Visser BW, Spaans F, Tavy DL, Koelman JH (2006) Interobserver variation in the interpretation of SSEPs in anoxicischaemic coma. Clinical Neurophysiol: Off J Int Fed of Clin Neurophysiol 117:1529-1535

71. Pfeifer R, Weitzel S, Gunther A, Berrouschot J, Fischer M, Isenmann S, Figulla HR (2013) Investigation of the inter-observer variability effect on the prognostic value of somatosensory evoked potentials of the median nerve (SSEP) in cardiac arrest survivors using an SSEP classification. Resuscitation 84:1375-1381

72. Geocadin RG, Buitrago MM, Torbey MT, Chandra-Strobos N, Williams MA, Kaplan PW (2006) Neurologic prognosis and withdrawal of life support after resuscitation from cardiac arrest. Neurology 67:105-108

73. Noirhomme Q, Lehembre R, Lugo ZD, Lesenfants D, Luxen A, Laureys S, Oddo M, Rossetti AO (2014) Automated Analysis of Background EEG and Reactivity During Therapeutic Hypothermia in Comatose Patients After Cardiac Arrest. Clin EEG Neurosci 45:6-13

74. Wennervirta JE, Ermes MJ, Tiainen SM, Salmi TK, Hynninen MS, Sarkela MO, Hynynen MJ, Stenman UH, Viertio-Oja HE, Saastamoinen KP, Pettila VY, Vakkuri AP (2009) Hypothermia-treated cardiac arrest patients with good neurological outcome differ early in quantitative variables of EEG suppression and epileptiform activity. Crit Care Med 37:2427-2435

75. Rossetti AO, Oddo M, Liaudet L, Kaplan PW (2009) Predictors of awakening from postanoxic status epilepticus after therapeutic hypothermia. Neurology 72:744-749
76. Rundgren M, Westhall E, Cronberg T, Rosen I, Friberg H (2010) Continuous amplitude-integrated

electroencephalogram predicts outcome in hypothermia-treated cardiac arrest patients. Crit Care Med 38:1838-1844

77. Hirsch LJ, Laroche SM, Gaspard N, Gerard E, Svoronos A, Herman ST, Mani R, Arif H, Jette N, Minazad Y, Kerrigan JF, Vespa P, Hantus S, Claassen J, Young GB, So E, Kaplan PW, Nuwer MR, Fountain NB, Drislane FW (2013) American clinical neurophysiology society's standardized critical care EEG terminology: 2012 version. J Clin Neurophysiol 30:1-27

78. Cloostermans MC, van Meulen FB, Eertman CJ, Hom HW, van Putten MJ (2012) Continuous electroencephalography monitoring for early prediction of neurological outcome in postanoxic patients after cardiac arrest: a prospective cohort study. Crit Care Med 40:2867-2875

79. Seder DB, Fraser GL, Robbins T, Libby L, Riker RR (2010) The bispectral index and suppression ratio are very early predictors of neurological outcome during therapeutic hypothermia after cardiac arrest. Int Care Med 36:281-288

80. Stammet P, Werer C, Mertens L, Lorang C, Hemmer M (2009) Bispectral index (BIS) helps predicting bad neurological outcome in comatose survivors after cardiac arrest and induced therapeutic hypothermia. Resuscitation 80:437-442

81. Leary M, Fried DA, Gaieski DF, Merchant RM, Fuchs BD, Kolansky DM, Edelson DP, Abella BS (2010) Neurologic prognostication and bispectral index monitoring after resuscitation from cardiac arrest. Resuscitation 81:1133-1137

82. Stammet P, Wagner DR, Gilson G, Devaux Y (2013) Modeling serum level of S100B and bispectral index to predict outcome after cardiac arrest. J Am Coll Cardiol 82:851-858

83. Reilly EL (1993) EEG Recording and operation of the apparatus. In: Niedermeyer E, Lopes da Silva F, Electroencephalography. Basic principles, clinical applications and related fields. Williams and Wilkins, Baltimore, pp 104-124

84. Kawai M, Thapalia U, Verma A (2011) Outcome from therapeutic hypothermia and EEG. J Clin Neurophysiol 28:483-488 
85. Oh SH, Park KN, Kim YM, Kim HJ, Youn CS, Kim SH, Choi SP, Kim SC, Shon YM (2012) The prognostic value of continuous amplitude-integrated electroencephalogram applied immediately after return of spontaneous circulation in therapeutic hypothermia-treated cardiac arrest patients. Resuscitation 84:200-205

86. Mani R, Schmitt SE, Mazer M, Putt ME, Gaieski DF (2012) The frequency and timing of epileptiform activity on continuous electroencephalogram in comatose post-cardiac arrest syndrome patients treated with therapeutic hypothermia. Resuscitation 83:840-847

87. Pfeifer R, Borner A, Krack A, Sigusch HH, Surber R, Figulla HR (2005) Outcome after cardiac arrest: predictive values and limitations of the neuroproteins neuron-specific enolase and protein S-100 and the Glasgow Coma Scale. Resuscitation 65:49-55

88. Kim J, Choi BS, Kim K, Jung C, Lee JH, Jo YH, Rhee JE, Kim T, Kang KW (2012) Prognostic performance of diffusion-weighted MRI combined with NSE in comatose cardiac arrest survivors treated with mild hypothermia. Neurocrit Care 17:412-420

89. Oksanen T, Tiainen M, Skrifvars MB, Varpula T, Kuitunen A, Castren M, Pettila V (2009) Predictive power of serum NSE and OHCA score regarding 6 month neurologic outcome after out-of-hospital ventricular fibrillation and therapeutic hypothermia. Resuscitation 80:165-170

90. Rundgren M, Karlsson T, Nielsen N, Cronberg T, Johnsson P, Friberg $\mathrm{H}$ (2009) Neuron specific enolase and S-100B as predictors of outcome after cardiac arrest and induced hypothermia. Resuscitation 80:784-789

91. Storm C, Nee J, Jorres A, Leithner C, Hasper D, Ploner CJ (2012) Serial measurement of neuron specific enolase improves prognostication in cardiac arrest patients treated with hypothermia: a prospective study. Scand J Trauma Resusc Emerg Med 20:6

92. Tiainen M, Roine RO, Pettila V, Takkunen O (2003) Serum neuronspecific enolase and S-100B protein in cardiac arrest patients treated with hypothermia. Stroke 34:2881-2886

93. Cronberg T, Rundgren M, Westhall E, Englund E, Siemund R, Rosen I, Widner H, Friberg H (2011) Neuronspecific enolase correlates with other prognostic markers after cardiac arrest. Neurology 77:623-630
94. Huntgeburth M, Adler C, Rosenkranz S, Zobel C, Haupt WF, Dohmen C, Reuter H (2014) Changes in neuronspecific enolase are more suitable than its absolute serum levels for the prediction of neurologic outcome in hypothermia-treated patients with outof-hospital cardiac arrest. Neurocrit Care 20:358-366

95. Mussack T, Biberthaler P, Kanz KG, Wiedemann E, Gippner-Steppert C, Mutschler W, Jochum M (2002) Serum S-100B and interleukin-8 as predictive markers for comparative neurologic outcome analysis of patients after cardiac arrest and severe traumatic brain injury. Crit Care Med 30:2669-2674

96. Rosen H, Rosengren L, Herlitz J, Blomstrand C (1998) Increased serum levels of the S-100 protein are associated with hypoxic brain damage after cardiac arrest. Stroke 29:473-477

97. Rosen H, Sunnerhagen KS, Herlitz J, Blomstrand C, Rosengren L (2001) Serum levels of the brain-derived proteins S-100 and NSE predict longterm outcome after cardiac arrest. Resuscitation 49:183-191

98. Mortberg E, Zetterberg H, Nordmark J, Blennow K, Rosengren L, Rubertsson S (2011) S-100B is superior to NSE, BDNF and GFAP in predicting outcome of resuscitation from cardiac arrest with hypothermia treatment. Resuscitation 82:26-31

99. Bloomfield SM, McKinney J, Smith L, Brisman J (2007) Reliability of S100B in predicting severity of central nervous system injury. Neurocrit Care 6:121-138

100. Stern P, Bartos V, Uhrova J, Bezdickova D, Vanickova Z, Tichy V, Pelinkova K, Prusa R, Zima T (2007) Performance characteristics of seven neuron-specific enolase assays.

Tumour Biol: J Int Soci Oncodev Biol Med 28:84-92

101. Johnsson P, Blomquist S, Luhrs C, Malmkvist G, Alling C, Solem JO, Stahl E (2000) Neuron-specific enolase increases in plasma during and immediately after extracorporeal circulation. Ann Thorac Surg 69:750-754

102. Anderson RE, Hansson LO, Nilsson O, Dijlai-Merzoug R, Settergren G (2001) High serum S100B levels for trauma patients without head injuries. Neurosurgery 48:1255-1258 discussion 1258-1260
103. Inamasu $\mathrm{J}$, Miyatake $\mathrm{S}$, Tomioka $\mathrm{H}$, Suzuki M, Nakatsukasa M, Maeda N, Ito T, Arai K, Komura M, Kase K, Kobayashi K (2009) Subarachnoid haemorrhage as a cause of out-ofhospital cardiac arrest: a prospective computed tomography study.

Resuscitation 80:977-980

104. Morimoto Y, Kemmotsu O, Kitami K, Matsubara I, Tedo I (1993) Acute brain swelling after out-of-hospital cardiac arrest: pathogenesis and outcome. Crit Care Med 21:104-110

105. Inamasu J, Miyatake S, Suzuki M, Nakatsukasa M, Tomioka H, Honda M, Kase K, Kobayashi K (2010) Early CT signs in out-of-hospital cardiac arrest survivors: temporal profile and prognostic significance. Resuscitation 81:534-538

106. Kim SH, Choi SP, Park KN, Youn CS, Oh SH, Choi SM (2013) Early brain computed tomography findings are associated with outcome in patients treated with therapeutic hypothermia after out-of-hospital cardiac arrest. Scand J Trauma Resusc Emerg Med 21:57

107. Wijdicks EF, Campeau NG, Miller GM (2001) MR imaging in comatose survivors of cardiac resuscitation. AJNR Am J Neuroradiol 22:1561-1565

108. Els T, Kassubek J, Kubalek R, Klisch J (2004) Diffusion-weighted MRI during early global cerebral hypoxia: a predictor for clinical outcome? Acta Neurol Scand 110:361-367

109. Mlynash M, Campbell DM, Leproust EM, Fischbein NJ, Bammer R, Eyngorn I, Hsia AW, Moseley M, Wijman CA (2010) Temporal and spatial profile of brain diffusionweighted MRI after cardiac arrest. Stroke 41:1665-1672

110. Wu O, Sorensen AG, Benner T, Singhal AB, Furie KL, Greer DM (2009) Comatose patients with cardiac arrest: predicting clinical outcome with diffusion-weighted MR imaging. Radiology 252:173-181

111. Wijman CA, Mlynash M, Caulfield AF, Hsia AW, Eyngorn I, Bammer R, Fischbein N, Albers GW, Moseley M (2009) Prognostic value of brain diffusion-weighted imaging after cardiac arrest. Ann Neurol 65:394-402

112. Choi SP, Park KN, Park HK, Kim JY, Youn CS, Ahn KJ, Yim HW (2010) Diffusion-weighted magnetic resonance imaging for predicting the clinical outcome of comatose survivors after cardiac arrest: a cohort study. Crit Care 14:R17 
113. Luyt CE, Galanaud D, Perlbarg V, Vanhaudenhuyse A, Stevens RD, Gupta R, Besancenot H, Krainik A, Audibert G, Combes A, Chastre J, Benali H, Laureys S, Puybasset L (2012) Diffusion tensor imaging to predict long-term outcome after cardiac arrest: a bicentric pilot study. Anesthesiology 117:1311-1321

114. Benali $\mathrm{H}$, van der Eerden AW, Khalilzadeh O, Perlbarg V, Dinkel J, Sanchez P, Vos PE, Luyt CE, Stevens RD, Menjot de Champfleur N, Delmaire C, Tollard E, Gupta R, Dormont D, Laureys S, Benali H, Vanhaudenhuyse A, Galanaud D, Puybasset L, Consortium N (2014) White matter changes in comatose survivors of anoxic ischemic encephalopathy and traumatic brain injury: comparative diffusion-tensor imaging study. Radiology 270:506-516

115. Maas AI, Hukkelhoven CW, Marshall LF, Steyerberg EW (2005) Prediction of outcome in traumatic brain injury with computed tomographic characteristics: a comparison between the computed tomographic classification and combinations of computed tomographic predictors. Neurosurgery 57:1173-1182 discussion 1173-1182

116. Cronberg T, Horn J, Kuiper MA, Friberg H, Nielsen N (2013) A structured approach to neurologic prognostication in clinical cardiac arrest trials. Scand J Trauma Resusc Emerg Med 21:45

117. Jorgensen EO, Holm S (1998) The natural course of neurological recovery following cardiopulmonary resuscitation. Resuscitation 36:111-122
118. Fritz HG, Holzmayr M, Walter B, Moeritz KU, Lupp A, Bauer R (2005) The effect of mild hypothermia on plasma fentanyl concentration and biotransformation in juvenile pigs. Anesthesia Analg 100:996-1002

119. Beaufort AM, Wierda JM, Belopavlovic M, Nederveen PJ, Kleef UW, Agoston S (1995) The influence of hypothermia (surface cooling) on the time-course of action and on the pharmacokinetics of rocuronium in humans. Eur J Anaesthesiol Suppl 11:95-106

120. Caldwell JE, Heier T, Wright PM, Lin S, McCarthy G, Szenohradszky J, Sharma ML, Hing JP, Schroeder M, Sessler DI (2000) Temperaturedependent pharmacokinetics and pharmacodynamics of vecuronium. Anesthesiology 92:84-93

121. Cronberg T, Brizzi M, Liedholm LJ, Rosen I, Rubertsson S, Rylander C, Friberg H (2013) Neurological prognostication after cardiac arrestrecommendations from the Swedish Resuscitation Council. Resuscitation 84:867-872

122. Taccone FS, Cronberg T, Friberg H, Greer D, Horn J, Oddo M, Scolletta S, Vincent JL (2014) How to assess prognosis after cardiac arrest and therapeutic hypothermia. Crit Care 18:202

123. Al Thenayan E, Savard M, Sharpe M, Norton L, Young B (2008) Predictors of poor neurologic outcome after induced mild hypothermia following cardiac arrest. Neurology 71:1535-1537
124. Nielsen N, Wetterslev J, Cronberg T, Erlinge D, Gasche Y, Hassager C, Horn J, Hovdenes J, Kjaergaard J, Kuiper M, Pellis T, Stammet P, Wanscher M, Wise MP, Aneman A, Al-Subaie N, Boesgaard S, BroJeppesen J, Brunetti I, Bugge JF, Hingston CD, Juffermans NP, Koopmans M, Kober L, Langorgen J, Lilja G, Moller JE, Rundgren M, Rylander C, Smid O, Werer C, Winkel P, Friberg H (2013) Targeted temperature management at $33^{\circ} \mathrm{C}$ versus $36^{\circ} \mathrm{C}$ after cardiac arrest. N Engl J Med 369:2197-2206

125. Grossestreuer AV, Abella BS, Leary M, Perman SM, Fuchs BD, Kolansky DM, Beylin ME, Gaieski DF (2013) Time to awakening and neurologic outcome in therapeutic hypothermiatreated cardiac arrest patients. Resuscitation 84:1741-1746

126. Gold B, Puertas L, Davis SP, Metzger A, Yannopoulos D, Oakes DA, Lick CJ, Gillquist DL, Holm SY, Olsen JD, Jain S, Lurie KG (2014) Awakening after cardiac arrest and post resuscitation hypothermia: are we pulling the plug too early? Resuscitation 85:211-214

127. Sharshar T, Citerio G, Andrews PJ, Chieregato A, Latronico N, Menon DK, Puybasset L, Sandroni C, Stevens RD (2014) Neurological examination of critically ill patients: a pragmatic approach. Report of an ESICM expert panel. Intensive Care Med 40:484-495 